where treatment would be carried out on a co-ordinated basis from the beginning to the end of the case, with the full co-operation of industry at all stages. At the present time we often find that the septic finger is treated by the newly qualified house-surgeon. His experience, however, is being obtained at the expense of the working man, who may, as a result of treatment, have a permanently stiff finger, with concurrent loss of earning power. The problem is essentially one of fingers and eyes, not of fractures.

The mainstay of our voluntary hospitals is the various workmen's contributory schemes, and, to a lesser degree, employers' contributions. And for that reason the whole future of the system is at stake if adequate return for contributions is not received by the men themselves and by industry. In my experience complaints have already been lodged, and reasonably so, by groups of workmen and by industrial managements on this very point, and the whole question of hospital policy therefore becomes one of vital and fundamental importance in connexion with the problem at issue.

\section{The Return to Work}

Then comes the time when, either in the natural course of events or as a result of special effort, the man feels that he is ready to start work again. Here comes a real difficulty. It may be that he is permanently unfitted for his original employment and no alternative or light work is available; his job may have been taken over by another, and he finds himself workless; or it may be that he has some fear of a recurrence because of a hitherto undiscovered weakness, or because of an acquired distaste for that particular type of work. And so at this stage it becomes a real necessity for the final return to be supervised in detail by the doctor in the factory. I believe that only thus can rehabilitation be carried out in very many cases. Not only does he know the man's job and other available jobs in the same industry with the intimacy of long acquaintance, but from his personal knowledge of the foreman and manager he is able to obtain for the man just that modicum of indulgence for a short period of time which can be utterly essential in completing his rehabilitation. It is difficult to define in any exact terms what I mean. But in many ways it denotes what can be described as a type of fellowship and a common bond between men, which not only can be the final stage of treatment in its broadest sense but is also an essential requirement of all industrial relations at the present time.

(The second lecture, with bibliography, will appear in next week's issue.)

At the meeting of the Board of Directors of the FinneyHowell Research Foundation, Baltimore, fellowships were renewed for the following: Paul Clarence Aebersold, Ph.D., Margaret Esther Boyland (Royal Cancer Hospital, London), Alma Howard, Ph.D., Lloyd Marvin Joshel, Ph.D., Lloyd William Law, Ph.D., Hermann Lisco, M.D., Charles Stuart McEuen, M.D., Walter C. Merkel, M.D. Fellowships were awarded for 1939 to G. M. Badger, M.S., of Melbourne, Australia, to work at the Royal Cancer Hospital, London; Arthur Kirschbaum, Ph.D., to work at Yale University; J. L. Melnick, Ph.D., to work at Yale University ; John F. Menke, M.D., to work at Stanford University Hospital, San Francisco; John L. Wood, Ph.D., to work at Harvard University; Paul C. Zamecnik, M.D., to work at the University of Carlsberg, Copenhagen. Grants-in-aid were also awarded to: Drs. R. D. Fowler, R. Walter Graham, jun., and George O. Gey. Applications for 1940 awards must reach the office of the Foundation, 1211, Cathedral Street, Baltimore, Maryland, U.S.A., by January 1, 1940.

\section{FOREIGN BODIES *}

\author{
BY
}

IAN FRASER, M.D., M.Ch., F.R.C.S.Eng., F.R.C.S.I. Assistant Surgeon, Belfast Hospital for Sick Children

A paper on foreign bodies is really a story of the human body. It refreshes our knowledge of anatomy, physiology, psychology, and legal medicine. It is not, as many think, merely an account of the vagaries of the lost article before its recovery. The first stand in the museum of the Royal College of Surgeons is covered with articles which have strayed into the human body by intention, by accident, or by surgical assistance, and which, after a sojourn there, have been recovered at operation, post mortem, or spontaneously.

The first of these to catch the eye is the cranking-handle of a tramcar-a Z-shaped iron bar some two feet in lengthwhich had entered the body in an unusual manner. The patient was descending the stairs of a moving tramcar. Having had a generous quantity of alcohol, he had lost his customary exactness of step, so that when the tram started somewhat suddenly he was projected backwards and sat down forcibly upon the control-box of the car. He felt acutely illnot without reason-and was transferred at once to hospital. On admission he was a mixture of shock and alcohol, but as soon as advisable he was operated upon. It was found that the handle, after piercing the seat of his trousers, had entered the anus and mounted the rectum. It had then gone into the pelvic colon, and later had cut into the peritoneal cavity. At the operation the various rents and tears were sewn up, including a hole in the bladder, and the man made an uninterrupted recovery. The honours of the case are divided equally between the dexterity and skill of the surgeon - Mr. Brook-and the physical endurance of the patient.

Articles usually enter the alimentary canal by being either swallowed at the upper end or pushed into the bowel at the lower end. Of the swallowed articles there is usually little to say. They are seen weekly in our hospitals, especially the children's hospital, with possibly a peak rise at Christmas, Hallowe en, and birthdays. Most of the smaller articles can pass through quite easily. It may be taken as a rough guide that anything which can go down the oesophagus and enter the stomach will be able to leave it, and then make the journey of thirty-five feet or so to the anus without difficulty. In fact the doctor's main duty will be to remember that "they also serve who only stand and wait." Coins, brooches, small toys, whistles, stones, false teeth, etc., are many of the examples often seen. Recently I had under my care a small boy of 10 years who had swallowed seventeen marbles. This boy said that he had been attacked by bigger boys and forced to swallow them; while they in turn said that the boy, having earned such applause for the first marble, kept repeating the trick. Although the police were called in, no satisfactory solution has ever been reached (Figs. 1 and 2). One still has to operate upon the odd case of the open safety-pin, which catches and cannot pass; the coin-a penny-which is too large; and that dangerous article of female attire the Kirby grip, which may fail to pass through the pylorus and negotiate what might almost be called the "hair-pin bends" of the duodenum.

A case which occurred in my own house is worth mentioning. It was when a 3-months-old cocker spaniel swallowed a small rubber toy duck. Aperients proved

* The substance of the presidential address to the Belfast Medical Students Association. 
useless, and although emetics produced a generous result the duck refused to reappear. An oesophagoscope was passed into the animal's stomach without locating the duck, and eventually I had to operate upon him. It is

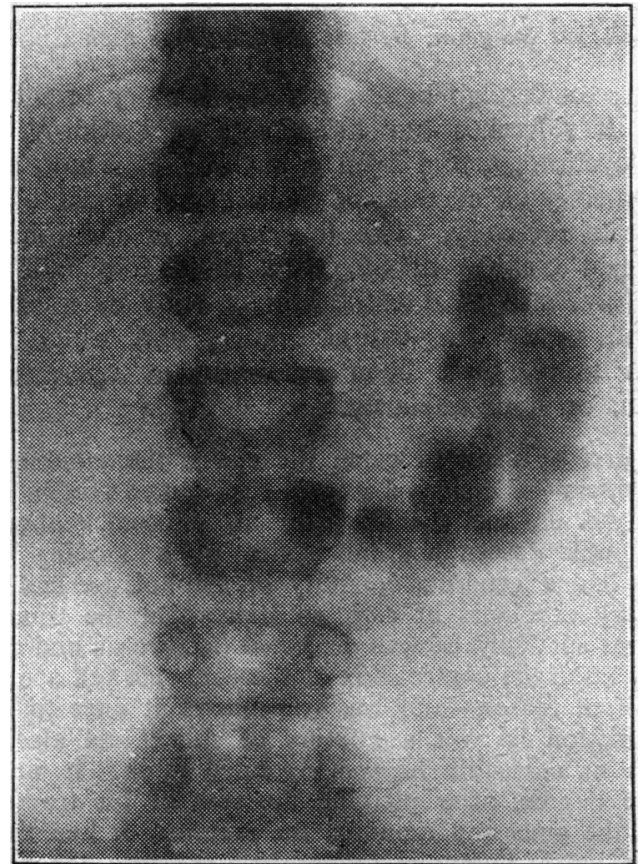

Fig. 1.-The marbles in the stomach.

interesting to note that the rubber had swollen to twice its size, which we should remember when dealing with a human case (Fig. 3).

\section{Professional Swallowers}

Swallowed articles are usually found in imbeciles and children, and perhaps in cases of crude attempts at suicide ; also occasionally in cases of perverted appetite arising in pregnancy, or in cases of accidental swallowing when consciousness has possibly been dulled by alcohol or by an anaesthetic-and woe betide the nurse who allows a patient to have an anaesthetic with the dental plate still in position! The most interesting group, however, are the professional swallowers, who make a livelihood by giving exhibitions of their skill or daring. Thorek, in describing a personal case, gives a most interesting account of other recorded cases, which are really very similar.

Thorek's case was that of a man of 24 years, a Canadian, who at the age of 4 had discovered with what ease swallowed articles were able to pass through, and so, achieving some little success at school with his efforts, decided to make this his profession. All went well until the age of 24, when affairs came to a head and, suffering acute pain, he was admitted to hospital for an immediate operation. When his stomach was opened and decarbonized it was found to contain some 276 articles, including upholstery tacks, nails, nuts, screws, tack heads, safety-pins, paper clips, bolts, curtain rings, washers, cartridges, coins, a can opener, a thumb tack, and a beer check. There was only one beer check: one would have thought that a larger quantity of this fluid would have been required to wash these down! Most of the articles were in an advanced state of rust, and they had caused severe gastritis with a large ulcer at one point. The man, contrary to the laws of surgery, made a rapid recovery and left hospital with a solemn promise to change his mode of living; within a few weeks, however, he was again back at his former profession.
Thorek, reviewing the cases up to date, worked out that 80 per cent. of the patients recovered after surgical removal-most of the deaths being, in fact, among swordswallowers, where the end of the sword had either pierced

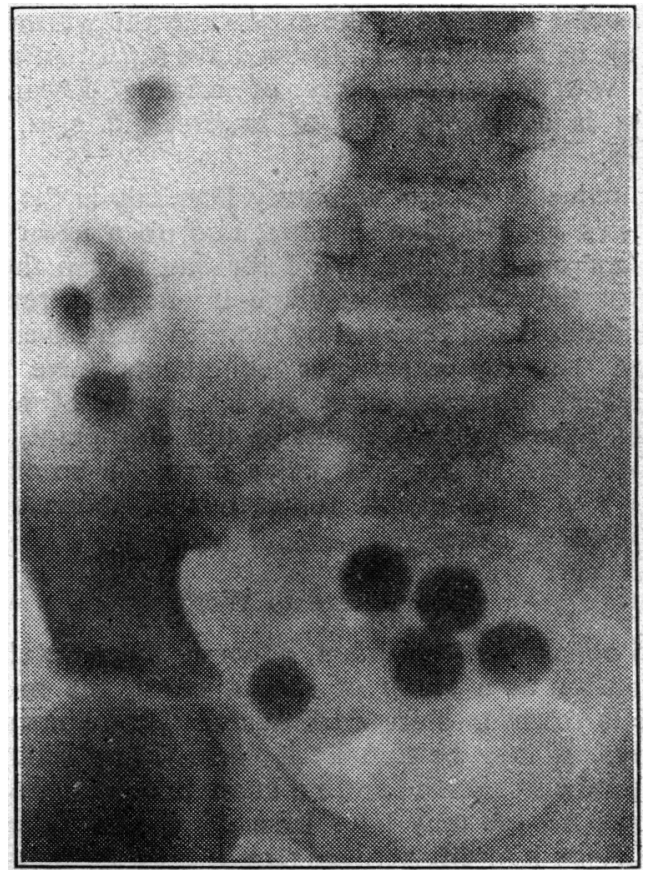

Fig. 2.-The marbles scattered through the intestine.

the stomach or broken off. In 1903 some ninety cases had been described, and with modern surgery the mortality rate is 10 per cent., which is very good when one realizes the state of the interior of the stomach after a dose of scrap-iron. With the professional swallowers penknives, watches, chains, keys, etc., appear to be the favourites; whereas with lunatics it seems more often to be nails, pins, broken glass, china, or eating implements such as knives, forks, or spoons.

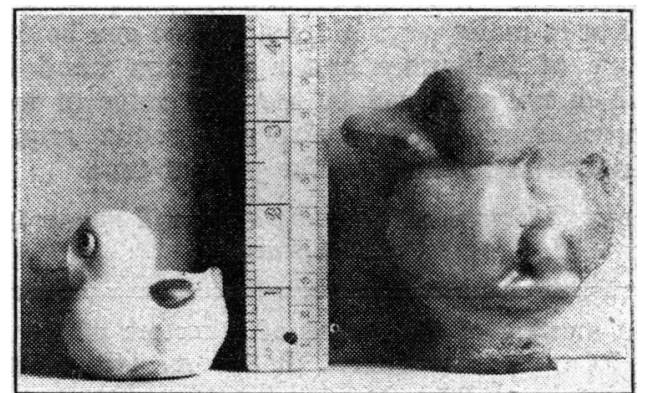

Fig. 3.- Rubber duck before and after being swallowed.

\section{Lunatics and Emperors}

The cases reported from asylums are so numerous that it is difficult to choose a suitable example. Agnew found in the intestines of one patient a mass of straw, three large roller bandages, and a pair of suspenders! There is also the case of the Danish Jewess who had a habit of swallowing sewing-needles. These usually worked their way to the surface, forming an abscess under the skin which had to be opened. In one year this remarkable lady was relieved of 273 needles in this way, and at the end of that time her abdomen, scarred by her surgical 
adventures, looked like the map of China. Notwithstanding all this, two years later she developed a large abscess in the axilla, and from it there were removed a further 100 needles.

There are some historical cases of swallowing foreign bodies. There is the famous shoe-buckle, on view for many years in Berlin, swallowed by Friedrich Wilhelm I in December, 1692, in his fifth year. This fortunately passed the opening of the windpipe and, hastened by a few grains of rhubarb, returned to the light of day. Had this not been so Frederick the Great would never have been born, and the map and history of Europe might have been greatly altered.

The swallowing of articles as a temporary "safedeposit" has been practised. In A.D. 70, when Titus, son of the Emperor Vespasian, was besieging Jerusalem with a mighty army, pitiful bands of deserters began to crawl out from the city towards the Roman lines. An observer says that they were "puffed up by the famine and swelled like men in a dropsy." A ghastly fate awaited them. The rumour spread among the cut-throats and the bandits who hung like jackals on the fringe of the Roman Army that the deserters had swallowed their gold before leaving the city. In one night 2,000 of these miserable wretches were slit open. Despite an order that any soldier found guilty of such a laparotomy upon a deserter would be executed, the practice did not stop. There is also the famous case of Mahomet II, who gave an order that all his fourteen pages should have their bellies slit open to find which one had stolen a piece of his melon.

\section{Miners' Eggs and Mixed Grills}

Leaving the upper part of the alimentary canal and going to the lower bowel we find again that many interesting cases have been recorded. We will pass over those of Voodooism reported from the East, where, for religious reasons and perverted sexual causes, foreign bodies were inserted into the rectum ; and also that uninteresting group of articles which have entered from above and would pass out in the normal course of events. Of these there is only one case worth mentioning, and that is the one in which I saw a former chief of my own do a rectal examination and withdraw two or three feet of a Ryle's stomach tube.

One of the most interesting rectal cases is the "miner's egg." In the silver mines in Chile it was usual to strip the miner before leaving the mine to see that he had nothing concealed on his person or in his mouth, ear, or nose. Thus the custom arose for these men to mould around a valuable piece of silver some wax-probably from their candles-and then fold this in an old piece of cloth, often a bit of shirt. The whole.mass, like an egg, was then pushed into the rectum, and when the man got home he was able to emulate the goose and the golden egg. This habit is not unattended with risk.

During the war Mende described the method employed by some Russian soldiers in order to escape war service. They inserted into the rectum small bags of dried peas; with the moisture these peas began to swell, and the bag was gently pulled until it brought down the lining of the bowel. This was repeated at regular intervals, and eventually a well-formed rectal prolapse was formed, which made marching and further military service at the time impossible.

Absorption from the rectum has long been recognized. At the present time one is satisfied with simple solutions such as tap-water or saline or glucose, as a contrast to the mixed grills that at one time were optimistically injected, such as cream, eggs, soup, and coffee. That absorption can take place is well exemplified in the case described by Landerer. A certain lady, to gain her foul ends and obtain a large inheritance, inserted into the rectum of the boy who stood in her way the heads of some phosphorus matches. There arose at once great pain and inflammation, from which the boy died the same evening. The woman was put in prison, but she committed suicide rather than stand her trial. Glaister reports how a convict was admitted to Liverpool prison in excellent health, but was found four hours later in a state of collapse, with nausea, vomiting, and paralysis of the legs. He had hidden an ounce of cut Cavendish tobacco in his rectum to convey it past the searchers.

\section{Ear, Nose, and Throat}

In the nose foreign bodies have lain for many years, either unsuspected or else the undiagnosed cause of illhealth, and the case of the dry pea that began to sprout is known to all. The mouth has often been used as a hiding-place to convey precious gems past dangerous places. One well-known case was that of the Indian prisoner who, by the constant pressure of a heavy bullet, was able to produce a pouch or purse behind his tongue. This pouch is present in every normal human being between the tongue and the epiglottis, and may give rise to serious trouble, but to enlarge it as an internal purse requires criminal ingenuity. Of foreign bodies inserted into the ear there have been countless cases. More damage has usually been caused by their unskilled removal than by their presence. The old fallacy of the danger to the brain from the earwig, the bed-bug, etc., is now quite exploded, although in Egyptian times one of the more attractive methods of execution was to pour molten metal into the external ear. Specimens of skulls containing these metal plugs have been dug up, and can be seen in many museums.

In the air passages the dangers from foreign bodies are great, and the mortality at one time was very high. The diagnosis was difficult, as $x$ rays had, not then been invented. It was in 1847 that Horace Green first suggested the method of internal illumination of the trachea and air passages. His claim was condemned as "an anatomical impossibility and unwarrantable innovation in practical medicine." He was at once asked to resign from his society. Now, with the perfection of electricity, with the skilled assistance of the instrument maker, and thanks to the invention of Roentgen, it is not only possible to locate a lost article in the intricate bronchial tree, but to grasp and remove it. To-day in the bronchoscopic clinics of one city alone there lie 3,300 recovered foreign bodies. The mortality in skilled hands is now 1 to 2 per cent., whereas in 1882, when a detailed study was made of 1,000 foreign bodies in the air passages, the death rate was appalling. Most of the recovered specimens had been obtained only by opening the windpipe or at necropsy. Unlike the lost article in the intestine, which is best treated, for a time at least, by "masterly inactivity"use a hackneyed phrase-the reverse applies to the air passages, when every minute counts.

Of articles that have gone under the skin the tales told are so tall that limits must be put upon our credulity. The following personal case shows how easy it is to overlook a foreign body such as glass, which does not show up on the $x$-ray plate. Glass varies in its opacity; depending upon its lead content. 
The patient in question was walking along a flat roof covered with snow, and so did not see a skylight. His first intimation of it was his sudden descent through the glass, on which he caught his hand. At hospital his wound was cleaned and sewn up; he healed rapidly, but his finger movements were poor. He sold his motor-bicycle, as he could not grip the handle-bars. After three months at the massage departmentwhere so often the impossible is expected-he thought he felt a grating. He came back to hospital, and from the centre of the palm a piece of plate glass the size of three pennies end to end was removed. It lay deep to the palmar fascia on the tendons, and so was not felt Recovery was inmediate (Fig. 4).

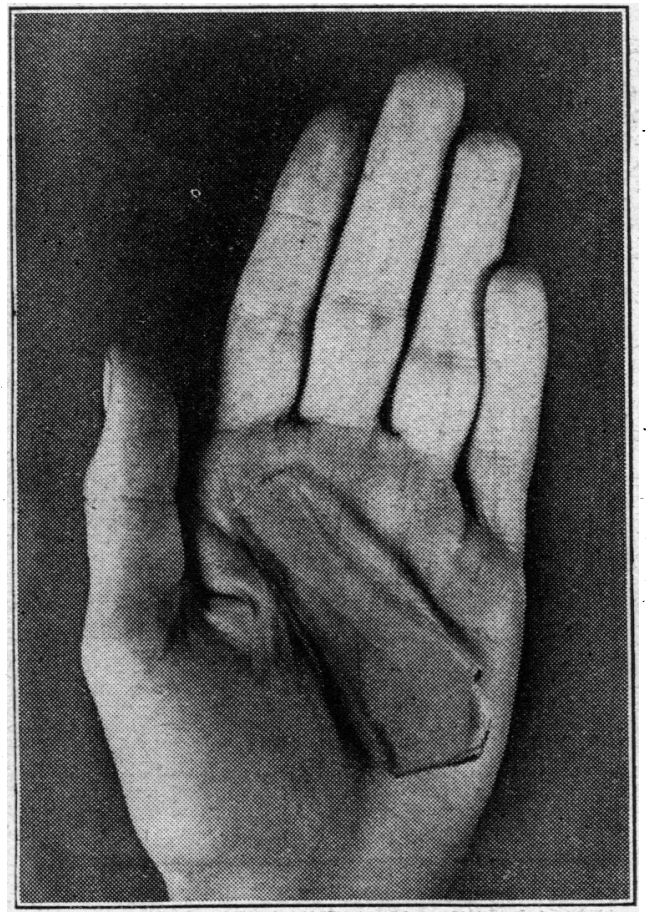

Fig. 4.-Glass in hand

\section{Surgical Foreign Bodies}

Certain surgical materials are occasionally left inside by accident or negligence. The symptoms that follow will depend upon whether the article is buried and becomes encysted or whether it is close to a hollow organ, to which it may adhere or into which it may ulcerate. I have removed from a bladder a swab which had worked its way there when a stone in the ureter was removed; and another, also from a bladder, which had been left behind during the repair of a femoral hernia. Such cases are not unusual.

Every museum has specimens of the lost forceps or scissors which have been removed by operation or at post-mortem examination after having lain in the abdomen for months or years. In some cases they have worked their way to the surface or penetrated into the bladder, uterus, vagina, or bowel. That such accidents can occur in the stress of the moment is easily understood. The patient is perhaps very ill and not taking the anaesthetic well; and with the rush to finish the operation and save his life something is overlooked. I have seen a swab removed from a wound in the groin. When one realizes the circumstances of this case-that of a boy who, when cutting a stick with a sharp knife, suddenly slit the femoral artery and was almost dead from haemorrhage before the vessel was finally caught and tied-the incident is understood. In the world at the moment publicity is given to such accidents rather than to the successes.
When a patient thinks such accidents are due to negligence he goes to law. On inquiry from one of the three medical protection societies I find that there are some 1,200 to 1,500 claims made annually, and of these 150 to 200 are for negligence. The public is getting more difficult, the lay press gives publicity to such incidents, and surgery is so much on the increase that these cases must occur more often. The patient is, as a rule, in the pleasant position of having nothing to lose and much to gain, while for the surgeon it is the opposite. He can lose not only a large sum of money but also his greatest assethis good name and reputation.

The first guinea earned by a young doctor should be spent in joining one of the medical protection societies. The surgeon may not be at fault, but there are so many others who deal with the case, dress it, etc., that the possibilities of error are great, yet the surgeon is legally responsible for the work of his servants and subordinates. Moynihan tells of a case where he ordered the wound to be packed each day with a small gauze dressing. At the end of thirty-three days he had to withdraw thirtythree swabs, which were tightly packed in. Incomplete instruction on his part and total lack of understanding on the nurse's were the causes of this.

\section{Cozening of a Cattle Dealer}

Foreign bodies in the female generative passages are so very common that space does not allow me to mention any, except one which happened recently in this city.

A lady relieved a cattle dealer of some $£ 80$ after enjoying a run to the country in his car; he discovered his loss quickly, and, calling at the police barracks, had the lady searched by a woman searcher. The result was negative. The police surgeon was then called in, and he found the missing money secreted in the vagina. A large wad containing four five-pound notes and sixty single pound notes was withdrawn.

In the male urethra many foreign bodies have been found. The common causes are possibly to stop dribbling in young children, masturbation in older children, and to keep the passages open in later years when the urinary stream is getting smaller owing to a stricture or enlarged prostate. An ivy leaf, a cigarette holder, thin sticks of plasticine, and candle wax are not uncommon. There is an unfortunate tendency for anything placed in the urethra to work its way back into the bladder rather than outwards, as one might expect. A case was reported a few years ago of a surgeon having removed a small snake from the bladder, into which it had been inserted some days before. To remove candle wax the ingenious method was devised of filling the bladder with water and then adding xylol. As the xylol rises to the surface it comes in contact with the wax which is floating there, and so, when the bladder is emptied, the dissolved wax is passed out as a milky fluid.

It will be seen that from the study of foreign bodies we gain an insight into the workings of the human body -what it can do to keep itself right, its powers of accommodation and defence, and where its weak points are. There is also an interesting historical side: and in addition we find in it a wide field for the study of human nature and its psychological problems-from the professional swallower to the criminal, the lunatic, the sexual pervert, not to mention the malingerer and the genuine case, such as the unfortunate gentleman with whom we started this somewhat rambling account, into whose fundament the cranking-handle of a tramcar had accidentally strayed. 


\section{BIBLIOGRAPHY}

Agnew, D. H. (1853). Medical Examiner, Philadelphia, n.s., 9, 346 Baer, H. L. (1935) Arch. Derm. Syph. Chicago, 32, 204.

Balfour, D. C. (1916). J. Amer. med. Ass., 66, 421

Brook, W. F. (1921). British Medical Journal, 2, 71

Bruce, G. G. (1931). Ibid., 2, 765.

Clerf, L. H. (1936). Ann. med. Hist., n.s., 8, 547.

Costedoat, A. (1933). La Simulation des Symptômes Pathologiques et des Maladies, Paris.

Credé, B. (1886). Arch. klin. Chir., 33, 574

Fieschi, D. (1938). Rev. Chir., Paris, 57,1.

Fraser, I. (1933). Lancet, 2, 921.

Friedenwald, J., and Rosenthal, L. J. (1903). N.Y. med. J., 78, 110

Geyerman, P. T. (1937) J. Amer med. Ass., 108, 1409.

Gould, G. M. and Pyle, W. L. (1898). Anomalies and Curiosities of Medicine, London.

Johnstone, I. L. (1935). British Medical Journal, 2, 546.

Kennedy, R. S. (1935). Ibid., 1, 1262.

Kidd, F. (1922). Proc. roy. Soc. Med., 15, Sect. Urol., 76

Kingsbury (1920). Arch. Derm. Syph., Chicago, 1, 737.

Kleinberg, S. (1926). Ann. Surg., 84, 616

Kränzle, P. (1900-1). Beitr. klin. Chir., 29, 327.

Landerer (1882). British Medical Journal, 1, 498.

Layton, T. B. (1930). Ibid., 1, 24.

Lewis, J. D. (1923). Ann. Otol. Rhinol. Laryngol., 32, 321.

Mason, F. (1870). Lancet, 1,701.

Mende, P. (1919). Mïnch. med. Wschr., 66, 94.

Montgomery, D. W., and Culver, G. D. (1926). J. Amer. med. Ass., 86, 92 .

Thorek, M. (1924). Int. Clin., 3, 282.

\section{EFFECT OF DESOXYCORTICOSTERONE ACETATE AND CORTIN ON SALT ELIMINATION IN ADDISON'S DISEASE}

\section{BY}

\author{
HARRY W. DRYERRE, M.B., Ch.B., M.R.C.P.Ed. \\ Clinical Tutor in Medicine, Royal Infirmary, Edinburgh; \\ Pathologist, Edinburgh Municipal Hospitals
}

(From the Clinical Laboratory, Royal Infirmary, Edinburgh)

It is exceedingly difficult to evaluate accurately the efficacy of the various therapeutic measures advocated for cases of adrenal cortical insufficiency. In the past workers have. depended mainly on their clinical impressions in making such estimations. More recently, following the demonstration by Loeb in 1932 of the abnormal serum ionic values that occur in cases of Addison's disease, many workers have sought to assess the progress of their patients by making repeated biochemical investigations on the blood. This is, however, by no means reliable, as the blood figures do not always reflect the clinical condition and may be quite abnormal in an apparently fit individual, and vice versa.

Cutler, Power, and Wilder (1938a, 1938b) have described a new test for adrenal insufficiency. In this the subject is given a low-sodium-chloride high-potassium diet for two and a half days, and the urinary sodium and chlorine concentration on the morning of the third day is estimated. While taking such a diet patients with Addison's disease appear to be unable to restrict the elimination of these ions despite their low blood serum ionic figures, whereas normal individuals, even if debilitated, excrete urine with a very low sodium and chlorine concentration. A paper has already been published corroborating the value of this test and suggesting slight modifications which appear to make it of even greater diagnostic value (Dryerre, 1939). The description of the technique, which has already been fully detailed in that paper, is not repeated here. It may, however, be stated briefly that whereas the cases of Addison's disease there described had a urinary sodium concentration of 160 to $298 \mathrm{mg}$. per $100 \mathrm{c.cm}$., control subjects in no instance showed a content above $70 \mathrm{mg}$. In view of this very considerable difference in urinary concentration between the affected and control subjects it was thought that it might be possible to make use of this test in a quantitative manner to evaluate suprarenal cortical extracts and their synthetic substitutes. For this purpose it was decided to apply the test at intervals to a known case of adrenal insufficiency. It was hoped in this way to find out the dose of each preparation that was necessary to restore the patient's urinary sodium content to a normal level. Failing this, it was anticipated that it might be possible to obtain an appreciable reduction in the sodium concentration in the urine that might be correlated with the amount of medicament administered.

An attempt was made to evaluate the potency of two preparations. The first of these was the standard cortical extract cortin (Organon). The second was desoxycorticosterone acetate (D.O.C.A.). This substance was first prepared in 1937 by Steiger and Reichstein, and consists of the acetic acid ester of a synthetic compound closely allied to corticosterone. This last is, as yet, the most active principle isolated in a pure state from the cortex of the suprarenal gland. The D.O.C.A. was available in two forms: (a) as tablets, each containing $50 \mathrm{mg}$.; and (b) in solution in arachis oil in a strength of $5 \mathrm{mg}$. per c.cm. Both the cortin and the D.O.C.A. were supplied through the courtesy of Dr. A. Macbeth and Organon Laboratories.

\section{The Subject of the Test}

In order to obtain results that could readily be correlated it was considered advisable to conduct all the investigations on a single case of adrenal insufficiency rather than on several patients, whose salt excretion figures might be difficult to compare. The subject was a known case of Addison's disease who had been maintained for four years principally by dietetic measures and large doses of sodium chloride, although specific cortical therapy had been necessary on several occasions at times of "crisis." He was aged 23, and had all the classical features of Addison's disease, with hypotension (90/60 approximately), skin and mucosal pigmentation, and very marked asthenia. He also suffered from bouts of nausea that had become noticeably less frequent and less severe following therapeutic measures.

\section{Technique}

The test described above was carried out on the subject at weekly intervals in a series of three experiments. The first of these (Tests I-V) was devoted to a study of the effects of cortin on the sodium and chlorine excretion; the second (Tests VI-IX) was used to determine the effect of the daily administration of D.O.C.A. by injection. Both preparations were given only on the day before the test and on the three days of the test. The third series (Tests X-XV) showed the effect of the implantation of $200 \mathrm{mg}$. of D.O.C.A. into the anterior abdominal wall of the patient. An interval of five weeks was allowed to elapse between the termination of the second series and the beginning of the third set of experiments to eliminate the possibility of a delayed effect from the previous injections. Owing to the low-sodium-chloride high-potassium content of the diet the test is often very exhausting to the subject and, although not so dangerous as the older sixday salt-restriction test, may readily cause a severe relapse. Accordingly the patient was carefully observed throughout the three days of each test, and adequate supplies of cortin were kept available in case of an emergency (Dryerre, 1939). 